\title{
Midterm outcome analysis of bipolar hemiarthroplasty for unstable intertrochanteric femur fractures: A retrospective study
}

Hongman CHO ( $\nabla$ chm1228@hanmail.net )

Gwangju Veterans Hospital https://orcid.org/0000-0001-5160-2640

\section{Sun Do Kim}

Gwangju Veterans Hospital

JiYeon Park

Gwangju Veterans Hospital

KiHyun Kwon

Gwangju Veterans Hospital

\section{Young Lee}

Veterans Medical Research Institute, Veterans Health Service Medical Center

Research article

Keywords: Hip, Intertrochanteric fracture, Osteoporosis, Bipolar hemiarthroplasty, Cementless stem

Posted Date: February 24th, 2020

DOI: https://doi.org/10.21203/rs.2.24322/v1

License: (c) (1) This work is licensed under a Creative Commons Attribution 4.0 International License. Read Full License 


\section{Abstract}

Background: Recent advances in medical systems and technologies have resulted in increased survival after intertrochanteric fractures of the femur, requiring the selection of appropriate femoral stems considering mid- to long-term durations. We performed hip hemiarthroplasty for unstable intertrochanteric fractures using a Wagner cone femoral stem (Group A) and double tapering right angled femoral stem (C2 stem, Group B), and evaluated the clinical imaging results.

Methods From January 2004 to December 2013, 79 patients (79 hips) who underwent hip hemiarthroplasty with a cone stem (36 cases) and C2 stem (43 cases) were included. During the followup period, clinically, changes in pain (visual analog scale [VAS] score), walking ability, and Harris Hip score were examined. Radiologically, changes in the proximal femur were observed. We also reviewed the complications that occurred.

Results Patients' mean ages were 77.2 (70-83) years and 78.6 (70-84) years, and mean follow-up periods were 84.7 (60-108) months and 85.4 (60-96) years in Groups A and B, respectively. Postoperative pain (VAS score) and the Harris hip score were not significantly different between the groups until 24 months and 36 months, respectively. However, VAS scores from 36 months postoperatively and Harris hip scores from 48 months postoperatively indicated that Group B patients had significantly higher VAS scores and lower Harris hip scores. There was no significant difference in walking ability between the groups; however, in Group B, walking ability was reduced by one grade in 13 patients and by two grades in nine. Cortical bone osteoporosis occurred in four and 14 cases in Groups A and B, respectively. In Group B, five patients developed cortical bone resorption, and four of them had nonunion of trochanteric fracture fragments.

Conclusions Hip hemiarthroplasty using a cementless femoral stem for unstable intertrochanteric fractures requires careful selection of the stem, considering the remaining life of the patient. When using a $3 \mathrm{C}$ stem for unstable intertrochanteric fractures, it is thought that the firm fixation of fractured trochanteric fragments is necessary, and for a reverse oblique fracture, it is better to use the 3B stem with a suitable length.

\section{Background}

Due to the increasing life expectancy and increasing physical activity of the elderly, the number of proximal femoral fractures worldwide is expected to rise from 1.6 to 6.3 million per year by the year 2050 [1]. Intertrochanteric femoral fractures are a common occurrence in the elderly and are often associated with high morbidity and mortality, owing to the associated comorbidities in this subset of patients [2]. For several decades, the treatment of choice for intertrochanteric fractures in elderly patients has been open reduction and internal fixation. However, primary bipolar hemiarthroplasty has been advocated as an alternative to osteosynthesis for unstable intertrochanteric fractures in the elderly, as it provides the advantages of permitting early full-weight bearing, avoiding the failures of osteosynthesis, and good 
functional outcomes and fewer complications [3]. Recently, various cementless stems have been developed to improve clinical outcomes and promote firm fixation. Furthermore, the use of cementless femoral stems is increasing and various designs and surface coated methods have been used for unstable intertrochanteric fractures with good results [3-9]. However, information on mid- to long-term outcomes following the use of a cementless stem in unstable intertrochanteric fractures is limited. Moreover, the ideal femoral stem for the treatment of an unstable intertrochanteric femoral fracture is still a matter of discussion. The study aimed to analyze retrospectively and compare the clinical and radiological outcomes of the Wagner cone femoral stem (Zimmer-Biomet, Warsaw, IN) and a doubletapered rectangular cross-section stem (C2 stem, Lima Corporate, Udine, Italy) in hemiarthroplasty for unstable intertrochanteric femur fractures.

\section{Materials And Methods}

\section{Participants}

Of 1312 patients ( 1467 hip joints) who were admitted and treated for intertrochanteric femoral fracture between January 2004 and December 2013, 181 patients (183 hips) underwent primary bipolar hemiarthroplasty. The inclusion criteria for hemiarthroplasty were the following: three or more unstable intertrochanteric fractures with a loss of posteromedial cortical buttress, patients aged 70 years or more, and severe osteoporosis (T-score < 2.5), and patients could perform activities alone or use walkingassistance tools (cane, walker) without being helped by others (independent ambulator). From this cohort, 102 patients were excluded. Exclusion criteria included those treated using an alternative prosthesis (except Wagner cone and C2 stem), polytrauma, or minimum follow-up of less than five years, and bilateral fracture. Therefore, the 79 patients ( 79 hips) satisfying the above criteria of enrollment were divided into two groups and results were compared. Group A comprised patients who had been treated with a Wagner cone femoral stem, and Group B patients treated with the C2 stem. For Groups A (36 patients, hips) and $B$ (43 patients, hips), the mean patient ages were $77.2(70-83)$ years and 78.6 (7084 ) years; male to female ratio, $12: 24$ and 16:27; mean follow-up period, $84.7(60-108)$ months and 85.4 (60-96) months, respectively. We analyzed and compared both groups for bone mineral density before hemiarthroplasty for the assessment of bone quality. The degree of osteoporosis was assessed based on the bone mineral density (T-score) in the contralateral hip area, which did not differ significantly between the $A$ and $B$ groups $(-2.9 \pm 0.8$ points vs. $-2.7 \pm 0.6$ points; $p=0.575)$. Preoperative radiographs were evaluated for Dorr type using the contralateral side femur [10]. Preoperative femoral geometry was classified using the Dorr classification system (Group A: type A [ $n=7$ ], type $B$ [ $=15]$, type $C[n=14]$, Group B: type $A[n=9]$, type $B[n=18]$, and type $C[n=16])$. Patients were classified into two subgroups (Group A, 3/36; Group B, 3/43) according to the reverse obliquity, and the clinical and radiological results were compared (Table 1). 
Table 1

Demographic data of Group A (Wagner cone femoral stem) and Group B (C2 stem)

\begin{tabular}{|lllll|}
\hline & & A group $(\mathbf{n}=\mathbf{3 6})$ & B group $(\mathbf{n}=43)$ & p value \\
\hline Age (year) & & $77.2(70-83)$ & $78.6(70-84)$ & 0.877 \\
\hline Gender & Male & 12 & 16 & 0.72 \\
\cline { 2 - 5 } & Female & 24 & 27 & \\
\hline Follow up (months) & & $84.7(60-108)$ & $85.4(60-96)$ & 0.713 \\
\hline BMD T score & & $-2.9 \pm 0.8$ & $-2.7 \pm 0.6$ & 0.575 \\
\hline Dorr type & A & 7 & 9 & 0.881 \\
\hline Fx Type & B & 15 & 18 & 0.821 \\
\hline Fx: fracture & C & 14 & 16 & \\
\hline BMD: bone mineral density & A22 & 36 & 43 & \\
\hline
\end{tabular}

\section{Evaluation Methods}

1) Evaluation of intra-operative results

Retrospective analysis was performed and information regarding operating time, amount of bleeding, postoperative blood transfusion, and orthopedic complications during the procedure or immediately postoperatively, and additional treatments were obtained from the patients' medical records. The operation time was evaluated from the start to the end of anesthesia. The total amount of blood lost during the surgery was measured as the sum of the volume of the blood collected through the suction bottle and the volume of the blood soaked gauze.

2) Clinical evaluations

Pain, walking ability, and functional status were clinically evaluated pre-and at each postoperative followup. Pain was evaluated using a visual analogue scale (range, $0-100$ ). Walking ability was evaluated as described below. The degree of capacity for activity at each follow-up was classified into three levels. Level 1 was defined by cases, where the patient could perform activities alone or use walking-assistance tools (cane, walker) without being helped by others (independent ambulator); level 2 were cases where the patient could perform activities only when helped by others (dependent ambulator); level 3 cases were those in which the patient could not conduct any activities other than moving in a wheelchair or resting in 
bed (nonfunctional ambulator) [11]. In addition, we compared full weight bearing ambulation between Groups A and B, where possible. Meanwhile, functional status was evaluated using the Harris hip score (HHS) [12]. Complications including dislocation and periprosthetic fracture were recorded.

3) Radiological evaluations

For the radiographic evaluation, the anteroposterior and the cross-table lateral view of the hip joint was used, which included the entire stem length. At each follow-up, radiographic images were compared with the index image obtained immediately postoperatively. Radiographic evaluation was performed by two independent observers who did not participate in the index procedure. Subsidence of the femoral component was defined as the change in the distance from the superolateral edge at the shoulder of the prosthesis to the line indicating the lower margin of both teardrop lines on the anteroposterior radiograph of the hip. Osteolytic lesions were defined according the criteria of Engh et al. [13]. Cortical porosis was defined as a decrease in bone mineralization resulting in a homogeneous but somewhat sparse (washedout) appearance of the remaining cortex [14]. In addition, we identified cases of endosteal cortical bone absorption around the femoral stem. We defined "endosteal cortical bone absorption as "divergent radiolucent lines greater than $1 \mathrm{~mm}$ " and performed additional analyses for these phenomena. Heterotopic ossification was classified according to the system of Brooker et al. [15] whenever present. We evaluated the union of fractured fragments of trochanteric areas, because we considered that the union of the trochanteric areas (proximal femur) could affect femoral stem fixation.

\section{Statistics}

Student's $t$ test and Mann-Whitney's $U$ test and Fisher's exact test were used to compare data between the groups and within each group, respectively. Two orthopedic residents who did not participate in the surgery assessed the results from the postoperative clinical and radiological studies. Kappa coefficient tests were applied for intra-rater (K1) and inter-rater (K2) reliability, and both categories were found to be at a reliable level $(K 1=0.88, K 2=0.81)$. All statistical analyses were performed using $R$ 3.5.1 $(R$ Foundation for Statistical Computing, Vienna, Austria), and all statistical tests were two-sided. P-values < 0.05 were considered statistically significant.

\section{Results}

\section{Perioperative data}

The mean operation time was $70 \pm 16$ minutes (Group A: $68 \pm 28$ minutes, Group B: $71 \pm 20$ minutes; $p=$ 0.521). Intraoperative blood loss was 755.5 (Group A: $375-1400 \mathrm{~mL}$, Group B: $380-1550 \mathrm{~mL} ; p=0.715$ ). Twenty-one patients (Group A: 9, Group B: 12; $p=0.771$ ) required postoperative blood transfusion; the mean number of transfused blood (packed RBC) units during hospital admission was $2.8 \pm 1.3$ in Group $A$ and $2.9 \pm 1.7$ in Group B. There were no significant differences in operation time, intraoperative blood loss, or transfusion requirement between the two groups. One case of acute immediate deep periprosthetic infection occurred in Group A. At 25 days after the operation, the patient was treated with a one-stage operation. After the exploration, extensive debridement and irrigation was performed. The head and bipolar cup were replaced, and deep periprosthetic infections improved. One femoral shaft fracture 
related to intraoperative procedure occurred during the insertion of the femoral stem in Group A. This fracture was fixed with wires, which healed completely without any additional operation. One case in Group B required revision surgery for hematoma. The drain was drawn on the day of surgery by patient under delirium, and the surgical site became tight and tensioned. Three days after the operation, the drain was re-inserted and the hematoma improved. There was no incidence of dislocation or differences of lower limb lengths above $1 \mathrm{~cm}$ in either group (Table 2).

Table 2

Perioperative results and complications of Group A and Group B

\begin{tabular}{|c|c|c|c|c|}
\hline & & A group $(n=36)$ & B group $(n=43)$ & $\mathrm{p}$ value \\
\hline \multicolumn{2}{|l|}{ op time (minute) } & $68 \pm 28$ & $71 \pm 20$ & 0.521 \\
\hline \multicolumn{2}{|l|}{ bleeding (ml) } & $762.9(375-1400)$ & $748.1(380-1550)$ & 0.715 \\
\hline \multicolumn{2}{|l|}{ transfusion patients } & 9 & 12 & 0.771 \\
\hline \multicolumn{2}{|l|}{ transfusion pRBC } & $2.8 \pm 1.3$ & $2.9 \pm 1.7$ & 0.885 \\
\hline \multirow[t]{3}{*}{ immediate complication } & Deep infection & 1 & 0 & 0.271 \\
\hline & hematoma & 0 & 1 & 0.357 \\
\hline & Intraop Fx. & 1 & 0 & 0.271 \\
\hline \multicolumn{5}{|l|}{ Op: operation } \\
\hline \multicolumn{5}{|c|}{ pRBC: packed red blood cells } \\
\hline \multicolumn{5}{|l|}{ Fx: fracture } \\
\hline Intraop: intraoperatively & & & & \\
\hline
\end{tabular}

\section{Clinical Results}

Full weight bearing was achieved similarly in both groups (Group A: $23.0 \pm 1.6$ days, Group B: $23.7 \pm 1.2$ days; $p=0.211$ ). Six weeks postoperatively, the pain level was decreased in both groups compared to the pre-and postoperative status with no significant differences found in both groups regarding pain levels up to 24 months. However, there were significant differences in both groups from the postoperative 36month evaluation $(p=0.032)$. Group A revealed higher evaluation of pain than Group B from 36 months postoperatively to the last follow-up. The evaluation of walking ability divided by the three grades did not significant differ between the two groups until the last follow-up. Among the patients in Group A, despite the capacity for activity was maintained at final follow-up in 25 patients, this declined by one level in eight patients, and declined by two levels in three patients. In Group B, 43 patients survived for at least five years after intertrochanteric fracture, while the capacity for activity was maintained at final follow-up in 21, declined by one level in 13 patients, and declined by two levels in nine patients $(p=0.051)$, approaching an acceptable significance level (Fig. 1) [11]. Postoperatively, there was no significant 
difference in the HHS for both groups until 36 months. However significant differences in both groups were found from postoperative 48 months $(p=0.034)$. Group A showed a higher HHS than Group B postoperatively at 48 months to the last follow-up. The mean HHS was $83.7 \pm 15.1$ (Group A) and $77.6 \pm$ 11.8 (Group B) at postoperative 60 months $(p=0.023)[12]$ (Fig. 1) (Table 3). 
Table 3

Clinical results of Group A and Group B

\begin{tabular}{|c|c|c|c|c|c|}
\hline & & & A group $(n=36)$ & B group $(n=43)$ & $\mathrm{p}$ value \\
\hline FWB (day) & & & $23 \pm 1.6$ & $23.7 \pm 1.2$ & 0.211 \\
\hline \multirow[t]{9}{*}{ Pain (VAS score) } & Pre-op & & $88.8(71-97)$ & $90.1(75-97)$ & 0.546 \\
\hline & Post-op & & $77.1(59-89)$ & $79.3(50-91)$ & 0.607 \\
\hline & 6 weeks & & $37.6(11-47)$ & $35.5(15-47)$ & 0.708 \\
\hline & 6 months & & $21.7(7-35)$ & $19.2(6-38)$ & 0.436 \\
\hline & 1 year & & $18.2(4-37)$ & $16.4(5-49)$ & 0.332 \\
\hline & 2 year & & $15.9(5-42)$ & $14.1(4-51)$ & 0.174 \\
\hline & 3 year & & $9.5(0-10)$ & $11.7(1-21)$ & 0.032 \\
\hline & 4 year & & $4.2(0-8)$ & $14.8(0-26)$ & 0.025 \\
\hline & 5 year & & $4.8(0-9)$ & $16.9(0-26)$ & 0.041 \\
\hline \multirow[t]{14}{*}{ walking ability } & & level 1 & 36 & 43 & \\
\hline & pre-op & level 2 & 0 & 0 & \\
\hline & & level 3 & 0 & 0 & \\
\hline & & level 1 & 28 & 32 & \\
\hline & 1 years & level 2 & 7 & 9 & 0.711 \\
\hline & & level 3 & 1 & 2 & \\
\hline & & level 1 & 25 & 31 & \\
\hline & 2 years & level 2 & 9 & 9 & 0.848 \\
\hline & & level 3 & 2 & 3 & \\
\hline & & level 1 & 25 & 24 & \\
\hline & 3 years & level 2 & 9 & 13 & 0.173 \\
\hline & & level 3 & 2 & 6 & \\
\hline & & level 1 & 25 & 22 & \\
\hline & 4 years & level 2 & 9 & 12 & 0.057 \\
\hline
\end{tabular}

FWB: full weight bearing

VAS: visual analog scale 


\begin{tabular}{|c|c|c|c|c|c|}
\hline & & & A group $(n=36)$ & B group $(n=43)$ & $\mathrm{p}$ value \\
\hline & & level 3 & 2 & 9 & \\
\hline & & level 1 & 25 & 21 & \\
\hline & 5 years & level 2 & 8 & 13 & 0.051 \\
\hline & & level 3 & 3 & 9 & \\
\hline \multirow[t]{6}{*}{ Harris hip score } & Pre-op & & $97.8 \pm 17.4$ & $96.2 \pm 19.8$ & 0.824 \\
\hline & 1 year & & $84.6 \pm 16.1$ & $85.9 \pm 22.5$ & 0.671 \\
\hline & 2 year & & $83.3 \pm 17.2$ & $84.5 \pm 15.6$ & 0.545 \\
\hline & 3 year & & $85.8 \pm 10.9$ & $80.5 \pm 13.7$ & 0.291 \\
\hline & 4 year & & $82.9 \pm 14.5$ & $77.4 \pm 14.4$ & 0.034 \\
\hline & 5 year & & $83.7 \pm 15.1$ & $77.6 \pm 11.8$ & 0.023 \\
\hline \multicolumn{6}{|c|}{ FWB: full weight bearing } \\
\hline \multicolumn{6}{|c|}{ VAS: visual analog scale } \\
\hline
\end{tabular}

\section{Radiological Results}

A subsidence of $5 \mathrm{~mm}$ of the femoral stem was observed in one case in Group $A$ at the six-week postoperative radiograph, which was not progressive on later radiographs. None of the stems showed radiographic signs of osteolysis. Cortical porosis was observed around the stem in 14 cases in Group B (four cases in Group A) from postoperative 12 months to 24 months (Fig. 2). Among the cortical porosis cases, endosteal cortical bone absorption (divergent radiolucent lines $>1 \mathrm{~mm}$ ) surrounding the stem was observed in five cases in Group B from postoperative 36 months to 60 months (no cases occurred in Group A) (Fig. 3). Trochanteric nonunion occurred in seven cases in Group A (reverse oblique fracture: one case) and 12 cases (reverse oblique fracture: three cases) in Group B (Table 4) (Fig. 4), and of the latter four cases showed endosteal cortical bone absorption (reverse oblique fracture: three cases). According to the Brooker classification system, heterotopic Grade I ossifications were observed in one case in Group A and in one case in Group B. Cortical bone porosis statistically significantly occurred in group 2 ( $p=$ 0.046), and endosteal cortical bone absorption occurred in five cases of group $B$, which only approached an acceptable significance level $(p=0.059)$. Finally, endosteal cortical bone absorption occurred in cases of cortical bone porosis (odds ratio: 34.16 ), nonunion of trochanteric fracture fragments (odds ratio: 10.76), and reverse oblique fracture (odds ratio: 107.8) (Table 4). 
Table 4

Radiological results and complications of Group A and Group B

\begin{tabular}{|c|c|c|c|c|}
\hline & & A group $(n=36)$ & B group $(n=43)$ & $\mathrm{p}$ value \\
\hline \multicolumn{2}{|c|}{ subcidence (> $5 \mathrm{~mm})$} & 1 & 0 & 0.271 \\
\hline \multicolumn{2}{|l|}{ cortical porosis } & 4 & 14 & 0.024 \\
\hline \multicolumn{2}{|c|}{ endosteal cortical bone absorption } & 0 & 5 & 0.035 \\
\hline \multicolumn{2}{|l|}{ trochanter nonunion } & 7 & 12 & 0.381 \\
\hline \multicolumn{2}{|c|}{ heterotrophic ossification } & 1 & 1 & 0.899 \\
\hline \multirow[t]{2}{*}{ late complications } & postop infection & 1 & 0 & 0.271 \\
\hline & periprosthetic fracture & 0 & 2 & 0.19 \\
\hline
\end{tabular}

Table 5

Risk factors of endosteal cortical bone absorption

\begin{tabular}{|c|c|c|c|c|c|c|c|c|c|}
\hline \multirow[t]{2}{*}{$\begin{array}{l}\text { risk } \\
\text { factor }\end{array}$} & \multicolumn{5}{|c|}{$\begin{array}{l}\text { endosteal cortical bone } \\
\text { absorption }\end{array}$} & \multirow[t]{2}{*}{ Odds ratio } & \multirow[t]{2}{*}{ low_Cl } & \multirow[t]{2}{*}{ up_Cl } & \multirow[t]{2}{*}{$p$ value } \\
\hline & ex & & & & & & & & \\
\hline exist & 5 & 9 & \multirow{3}{*}{$\begin{array}{l}\text { non } \\
\text { exist }\end{array}$} & 0 & 29 & 34.16 & 1.72 & 676.51 & 0.002 \\
\hline TFN & 4 & 8 & & 1 & 30 & 10.76 & 1.46 & 79.39 & 0.017 \\
\hline ROF & 3 & 0 & & 2 & 38 & 107.8 & 4.27 & 2718.38 & 0.001 \\
\hline \multicolumn{10}{|l|}{ CP: cortical porosis } \\
\hline \multicolumn{10}{|c|}{ TFN: trochanteric fracture nonunion } \\
\hline \multicolumn{10}{|c|}{ ROF: reverse oblique fracture } \\
\hline \multicolumn{10}{|c|}{ Cl: confidence interval } \\
\hline
\end{tabular}

\section{Complications}

One stem was revised due to periprosthetic infection at postoperative 6 months in Group A. Periprosthetic fractures in two patients occurred because of slip-down in Group B. One patient was treated by open reduction and internal fixation with wiring and plate. The other patient was treated with conservative treatment due to stable periprosthetic fracture (Vancouver classification Type AG fracture located at the proximal metaphysis, and involved the greater trochanter). None of the other stems required revision during the follow-up period (Table 4).

\section{Discussion}


Recently, the cementless stem has been widely used for hip arthroplasty and there have been many studies reporting good results for unstable intertrochanteric fractures [3-9]. However, studies evaluating the long-term outcomes patients who have survived for over five years or femoral stems applied using different fixation methods according to each design have been small studies. With recent advances in medical technology, the mortality rate after hip fractures has decreased significantly $[16,17]$. Therefore, patients subjected to surgical treatment for intertrochanteric fractures are more likely to survive for more than five years after hip fracture. Thus, the choice of surgical method (osteosynthesis or arthroplasty) is critical, and the choice to treat with arthroplasty or the selection of implants considering survival of over five years is important.

The cone stem applied in Group A was type 3B [18], and featured a conical design with a distal taper. Since its proximal portion is a relatively rounded cone, it can provide rotation in wide femoral metaphysis, and is mostly fixed in the distal regions [19]. Long-term survival of $91.5 \%$ at a mean of 11.5 years using these stems has been reported [20]. There have been several studies indicating good results for treatment of intertrochanteric fractures in elderly patients with osteoporosis using stem fixation on diaphysis [5]. Kayali et al. reported that good outcomes following the application of the type 3B cementless stem for 42 intertrochanteric fracture patients [6]. There are several studies about the results of using the type 3B stem for proximal femoral bone loss and osteotomy surgery, which are associated with a loss of continuity of the proximal femur, e.g., unstable intertrochanteric fractures. Robert et al. suggested that the Wagner stem has superior initial fixation stability over fully porous-coated cylindrical stems, in the setting of severe proximal femur bone loss, with only $3 \mathrm{~cm}$ of intact femoral diaphysis [21]. Zhu et al, reported that stable fixation by bone ingrowth was defined as no subsidence or radiolucent lines around the prosthesis for 21 Crowe type IV dysplastic hip patients using a type 3B cementless stem combined with transverse subtrochanteric femoral osteotomy [22]. Likewise, we present similar results, whereby type 3B cementless stems were stable in the early stage and had good mid- to long-term survival in patients with unstable intertrochanteric fractures. Although there were seven cases of fracture nonunion (with one case of reverse oblique fracture) and four cases of cortical osteoporosis, none progressed to endosteal cortical bone absorption. Cortical osteoporosis was identified in three cases of trochanter fragment nonunion cases and in one case of the union cases.

The C2 stem of Group B was a type 3C [18], which features a rectangular cross-section that obtains threepoint fixation in the metaphyseal diaphyseal junction of the femur below the lesser trochanter and its cross-section provides four-point rotational support [23]. The clinical experience with type $3 \mathrm{C}$ stem has been very good, with excellent results; the survival rate of the stems after ten years was $96 \%$, and the complication rate was very low [24]. However, poor bone ongrowth has been reported in the proximal region when using the type $3 \mathrm{C}$ stem in long-term follow-up [25]. Specifically, if the type $3 \mathrm{C}$ stem is used for intertrochanteric fractures in which the proximal region is fractured, the bone ongrowth of the proximal region may be poorer because the fixation force is mainly obtained in the diaphysis and stable three-point fixation cannot be achieved. Some studies have reported good results with type $3 \mathrm{C}$ stems for unstable intertrochanteric fractures $[3,7]$. However, studies that report excellent results using these type $3 \mathrm{C}$ stems have been mostly short-term. Lee et al. reported unstable intertrochanteric fractures using type 
3C stems (average follow-up: 36 months) and they found that the occurrence of cortical porosis around the femoral component in $30 \%$ of patients. These phenomena might provide some explanations for the observed porosis, and could represent stress shielding following the use of a cementless stem, and/or cortical thinning due to aging [8]. In terms of stability, Ha et al. reported that the cortical porosis did not threaten the stability of the stems for 2-6 years postoperatively [9]. However, Lee et al. reported that the cortical porosis did not threaten the stability of the femoral components for a minimum of 2 years postoperatively, whether this type of bone loss will eventually threaten implant stability is unknown. Thus, the authors suggested that a longer follow-up is necessary to assess the effects of the porosis on the longevity of implants, and this stem design should be used with caution in young active patients with a long life expectancy [8]. We also identified cortical porosis in 14 of 43 patients in Group B (32.6\%) and in four of 36 patients in Group A (11.1\%). This phenomenon appeared 12 months after surgery. Nine of 14 patients in Group B had no progression without improvement, but five progressed and showed endosteal cortical bone absorption combined with radiolucent lines between the femur stem and cortex. For the cementless femoral stem, proximal bone contact is widely recognized as necessary to decrease micromotion and facilitate osseointegration at the implant bone interface [26, 27]. Therefore, the lack of fixation in the proximal region could lead to high clinical failure rates [28]. The proximal portion of the femur is very important in order for the type $3 \mathrm{C}$ stem to achieve three-point fixation. If this portion is unstable, it may affect fixation or long-term stability of the stem. Sophia et al. used a type $3 \mathrm{C}$ stem for femurs with proximal femoral bone loss and tested the resulting micromotion [29]. Their study showed medial-lateral and anterior-posterior migrations in the nonfractured group, with significantly smaller migrations compared with the fractured group, with anterior-posterior migrations larger than mediallateral migrations. By design, the type 3 stem has a dual tapered design intended to enable the stem to fill the femoral canal in the coronal plane, without any regard to the sagittal plane filling $[30,31]$. Therefore, one would expect anterior-posterior motions to be higher than the medial-lateral motions. This may affect the increase in the micromotion of the stem fixed to the femur.

Kang et al. performed hip arthroplasty using a type $3 \mathrm{C}$ stem and reported radiological results after more than five years [32]. Of the 112 cases followed up, 15 cases (13.4\%) showed a radiolucent line, and there were significant cases of lack of calcar filling $(p=0.033)$, which may occur when the calcar fill is insufficient, as the proximal femoral region is wide in the case of a Dorr A type femur. The fine motion of the femoral stem causes bone resorption, and the fibrous membrane fills the gap between the femoral stem and inner cortex, which appears radiolucent on plain radiography [32]. Furthermore, Lutz et al, performed hip arthroplasty using a type $3 \mathrm{C}$ stem and analyzed the clinical and radiological outcomes determined by CT-assisted osteodensitometry of bone mineral density and bone mineral changes of the femoral cortical and cancellous bone [33]. At six years postoperatively, the cortical and cancellous bones of diaphysis around the stem tip showed a small decrease in bone density, but the cortical and cancellous bones of the metaphysis showed a significant decrease in bone density.

Although the threshold for ingrowth has been debated in the literature, several studies have reported that acceptable micromotions between 28-40 micrometers for bony ingrowth and up to 150 micrometers for fibrous ingrowth $[26,27]$. Thus, in the case of unstable intertrochanteric fractures, which are estimated to 
have more than 150 micrometers of micromotion in the proximal femoral cavity, motion beyond this range is possible even if the proximal fracture is firmly fixed. If the fractured proximal femur is a delayed union or does not achieve a complete union, the micromotion is expected to increase and other effects such as stress shielding may lead to radiolucent lines and endosteal cortical bone absorption. We identified 12 cases of trochanter fracture nonunion and 14 cases of cortical osteoporosis. Four cases that showed a fracture nonunion (three cases of reverse oblique fracture) and cortical osteoporosis, progressed to endosteal cortical bone absorption, and pain and function was significantly different from that of Group A from 36 months and 48 months after operation. However, the relationship could not be precisely defined; thus, additional cases are needed for long-term studies. We propose that this phenomenon occurred because the traditional fixation concept of type $3 \mathrm{C}$ stems was not achieved in intertrochanteric fractures (fixed to meta-diaphysis but mainly fixed to diaphysis). Although the fractured proximal portion was firmly fixed, a stable three-point fixation was not obtained. This may a reason for the increased micromotion of the femoral stems on the femur and the progression to insufficient fixation, while insufficient contact area may have led to incomplete bone ongrowth. We suggest that these factors influenced the changes in cortex of the proximal femur.

The present study has the following limitations. It is not a large-scale prospective study using femoral stems with various designs and surface coatings. In the future, a long-term study by many institutions is needed. In particular, considering the fractured proximal bone fragments in addition to the design of the stem, a comparative study comparing the surface coating of the stem is necessary to evaluate bone ingrowth and ongrowth better. Although not significant for walking evaluation, walking ability decreased in Group B from 48 months postoperatively. Our study also has a retrospective design, which has inherent limitations. In the future, it is necessary to score the evaluation of walking ability or to increase the grade to three or more for further evaluation prospectively. Lastly, investigation of whether cortical bone porosis, nonunion of trochanteric fracture fragments, and endosteal cortical bone absorption affected the reduction of ambulation capacity was not performed because of the lack of statistical value due to the small number of cases. Again, we believe that large-scale multicenter studies with more cases will be needed in the future.

\section{Conclusions}

Hip hemiarthroplasty using a cementless femoral stem for unstable intertrochanteric fractures can be used selectively in elderly patients and those with osteoporosis, considering early ambulation and low rate of complications. However, careful femoral stem selection regarding the design is needed considering the remaining life of the patient, and if a $3 \mathrm{C}$ stem is used, surgeons have to ensure firm fixation of the fractured trochanteric fragments in order to obtain sufficient three-point fixation in the proximal femur. Additionally, as with a reverse oblique fracture, when using a $3 \mathrm{C}$ stem or when it is difficult to achieve stable and firm fixation of the fracture fragments, it is better to use a stem with a suitable length and design that can be fixed in diaphysis mostly. 


\section{Abbreviations}

HHS

Harris hip score

\section{Declarations}

\section{Ethics approval and consent to participate}

The design and protocol of this retrospective study were approved by the institutional review board of the First Author's Hospital (GJVH-IRB No. 2019-6-2). All patients were informed that their medical data could be used in a scientific study and provided their consent.

\section{Availability of data and materials}

The datasets used and/or analyzed during the current study are available from the corresponding author on reasonable request.

\section{Competing interests}

The authors have no potential conflicts of interest to disclose.

\section{Funding}

Not applicable.

\section{Authors' contributions}

HMC conceived and coordinated the study. HMC, SDK, and JP designed the ethical issues. HMC and SDK acquired the data. HMC and SDK reviewed the data. YL and HMC performed the statistical analysis. HMC, JP, and KK prepared the manuscript. SDK, JP, and KK provided administrative, technical, or material support. All authors approved the manuscript.

\section{Acknowledgements}

Not applicable.

\section{Consent for publication}

Written informed consent was obtained from all patients.

\section{References}

1 Cooper C, Campion G, Melton LJ 3rd. Hip fractures in the elderly: A worldwide projection. Osteoporos Int. 1992;2:285-9. 
2 Rainfray M, Dehail P, Salles N Complications of immobility and bed rest. Prevention and management. Rev Prat. 2007;57:671-6

3 Park MS, Cho HM, Kim JH, Shin WJ. Cementless bipolar hemiarthroplasty using a rectangular crosssection stem for unstable intertrochanteric fractures. Hip Int. 2013;23:316-22.

4 Andress HJ, Kahl S, Kranz C, Gierer P, Schurmann M, Lob G. Clinical and finite element analysis of a modular femoral prosthesis consisting of a head and stem component in the treatment of pertrochanteric fractures. J Orthop Trauma. 2000;14:546-53.

5 Talmo CT, Bono JV. Treatment of intertrochanteric nonunion of proximal femur using the S-ROM prosthesis. Orthopaedics 2008;31:125. doi:10.3928/01477447-20080201-35.

6 Kayali C, Agus H, Ozluk S, Sanli CJ. Treatment for unstable intertrochanteric fractures in elderly patients: internal fixation versus cone hemiarthroplasty. Orthop Surg (Hong Kong). 2006;14:240-4.

7 Lee YK, Won H, Roa KRU, Ha YC, Koo KH. Bipolar hemiarthroplasty using microarc oxidation-coated cementless stem in patients with unstable intertrochanteric fracture. J Orthop Surg (Hong Kong). 2019;27:2309499019847815.

8 Lee YK, Ha YC, Chang BK, Kim KC, Kim TY, Koo KH. Cementless bipolar hemiarthroplasty using a hydroxyapatite-coated long stem for osteoporotic unstable intertrochanteric fractures. J Arthroplasty 2011;26:626-32.

9 Lee YK, Joung HY, Kim SH, Ha YC, Koo KH. Cementless bipolar hemiarthroplasty using a micro-arc oxidation coated stem in patients with displaced femoral neck fractures. J Arthroplasty 2014;29:2388-92.

10. Dorr LD, Faugere MC, Mackel AM, Gruen TA, Bognar B, Malluche HH. Structural and cellular assessment of bone quality of proximal femur. Bone. 1993;14:231-42.

11 Cho HM, Lee K, Min W, Choi YS, Lee HS, Mun HJ, et al. Survival and functional outcomes after hip fracture among nursing home residents. J Korean Med Sci. 2016;31:89-97.

12 Harris WH. Traumatic arthritis of the hip after dislocation and acetabular fractures: treatment by mold arthroplasty. An end-result study using a new method of result evaluation. J Bone Joint Surg Am. 1969;51:737-55.

13 Engh CA, Hooten Jr JP, Zettl-Schaffer KF, Ghaffarpour M, McGovern TF, Macalino GE, et al. Porouscoated total hip replacement. Clin Orthop Relat Res. 1994:89-96.

14 Lee YK, Ha YC, Chang BK, Kim KC, Kim TY, Koo KH. Cementless bipolar hemiarthroplasty using a hydroxyapatite-coated long stem for osteoporotic unstable intertrochanteric fractures. J Arthroplasty. 2011;4:626-32. 
15 Brooker AF, Bowerman JW, Robinson RA, Riley Jr LH. Ectopic ossification following total hip replacement. Incidence and a method of classification. J Bone Joint Surg Am. 1973;55:1629-32.

16 Guzon-Illescas O, Perez Fernandez E, Crespí Villarias N, Quirós Donate FJ, Peña M, Alonso-Blas C, et al. Mortality after osteoporotic hip fracture: incidence, trends, and associated factors. J Orthop Surg Res 2019;4;14:203. doi:10.1186/s13018-019-1226-6

17 Frost SA, Nguyen ND, Center JR, Eisman JA, Nguyen TV. Excess mortality attributable to hip-fracture: a relative survival analysis. Bone. 2013;56:23-9.

18 Khanuja HS, Vakil JJ, Goddard MS, Mont MA. Cementless femoral fixation in total hip arthroplasty. J Bone Joint Surg Am. 2011;93:500-9.

19 Yamada H, Yoshihara Y, Henmi O, Morita M, Shiromoto Y, Kawano T, et al. Cementless total hip replacement: past, present, and future. J Orthop Sci. 2009;14:228-41

20 Schuh A, Schraml A, Hohenberger G. Long-term results of the Wagner cone prosthesis. Int Orthop 2007;33:53-8.

21 Russell RD, Pierce W, Huo MH. Tapered vs. cylindrical stem fixation in a model of femoral bone deficiency in revision total hip arthroplasty. J Arthroplasty 2016;31:1352-5.

22 Zhu J, Shen C, Chen X, Cui Y, Peng J, Cai G. Total hip arthroplasty with a non-modular conical stem and transverse subtrochanteric osteotomy in treatment of high dislocated hips. J Arthroplasty. 2015;30:611-4.

23 Zweymüller K, Semlitsch M. Concept and material properties of a cementless hip prosthesis system with Al2O3 ceramic ball heads and wrought Ti-6Al-4V stems. Arch Orthop Trauma Surg. 1982;100:229-36.

24 Janda W, Hübl M, Stöckl B, Thaler, M, Labek, G. Performance of the Zweymüller total hip arthroplasty system: a literature review including arthroplasty register data. Eur Orthop Traumatol. 2010;1:9-15.

25 Affatato S, Comitini S, Fosco M, Toni A, Tigani D. Radiological identification of Zweymüller-type femoral stem prosthesis in revision cases. Int Orthop 2016;40:2261-9.

26 Engh CA, McGovern TF, Bobyn JD, Harris WH. A quantitative evaluation of periprosthetic boneremodeling after cementless total hip arthroplasty. J Bone Joint Surg Am. 1992;74:1009-20.

27 Engh CA, O'Connor D, Jasty M, McGovern TF, Bobyn JD, Harris WH. Quantification of implant micromotion, strain shielding, and bone resorption with porous-coated anatomic medullary locking femoral prostheses. Clin Orthop. 1992;285:13-29.

28 Paprosky WG, Greidanus NV, Antoniou J. Minimum 10-year-results of extensively porous-coated stems in revision hip arthroplasty. Clin Orthop Relat Res. 1999:369:230-42. 
29 Sangiorgio SN, Ebramzadeh E, Borkowski SL, Oakes DA, Reid JJ, Bengs BC. Effect of proximal femoral bone support on the fixation of a press-fit noncemented total hip replacement femoral component. J Appl Biomater Funct Mater. 2013;11:e26-34.

30 Delaunay C, Bonnomet F, North J, Jobard D, Cazeau C, Kempf JF. Grit-blasted titanium femoral stem in cementless primary total hip arthroplasty: a 5- to 10-year multicenter study. J Arthroplasty. 2001;16:47-54.

31 Delaunay C, Kapandji Al. Survival analysis of cementless grit-blasted titanium total hip arthroplasties. J Bone Joint Surg Br. 2001;83:408-13.

32 Kang JS, Ko SH, Na Y, Youn YH. Clinical and radiological outcomes of rectangular tapered cementless stem according to proximal femoral geometry in elderly Asian patients. Hip Pelvis. 2019;31:224-31.

33 Mueller LA, Nowak TE, Haeberle L, Mueller LP, Kress A, Voelk M, et al. Progressive femoral cortical and cancellous bone density loss after uncemented tapered-design stem fixation. Acta Orthop 2010;81:171-7.

\section{Figures}

\section{(A) Harris hip score}

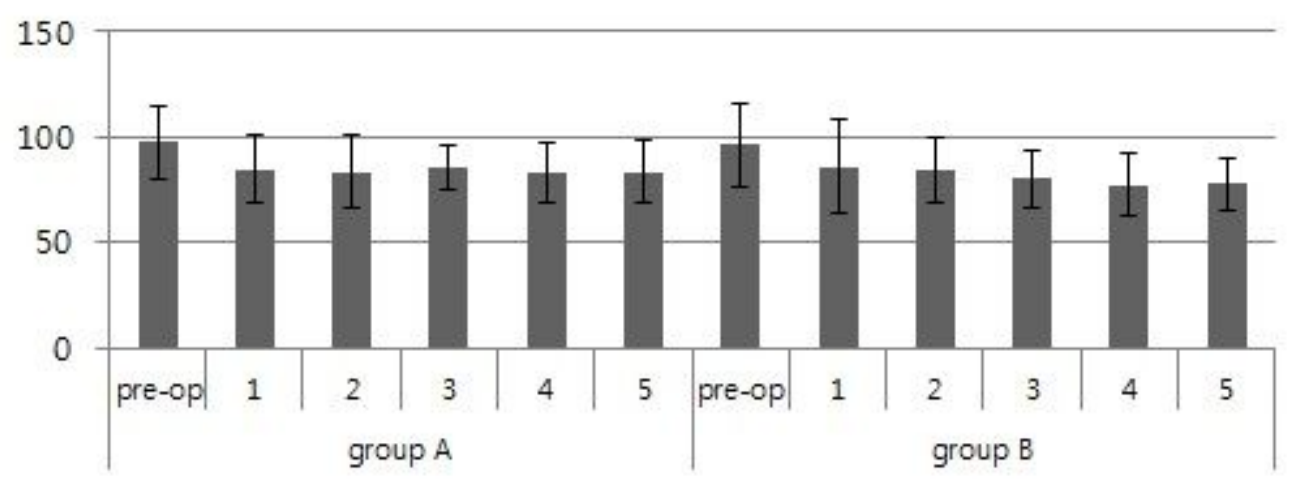

(B) Walking ability

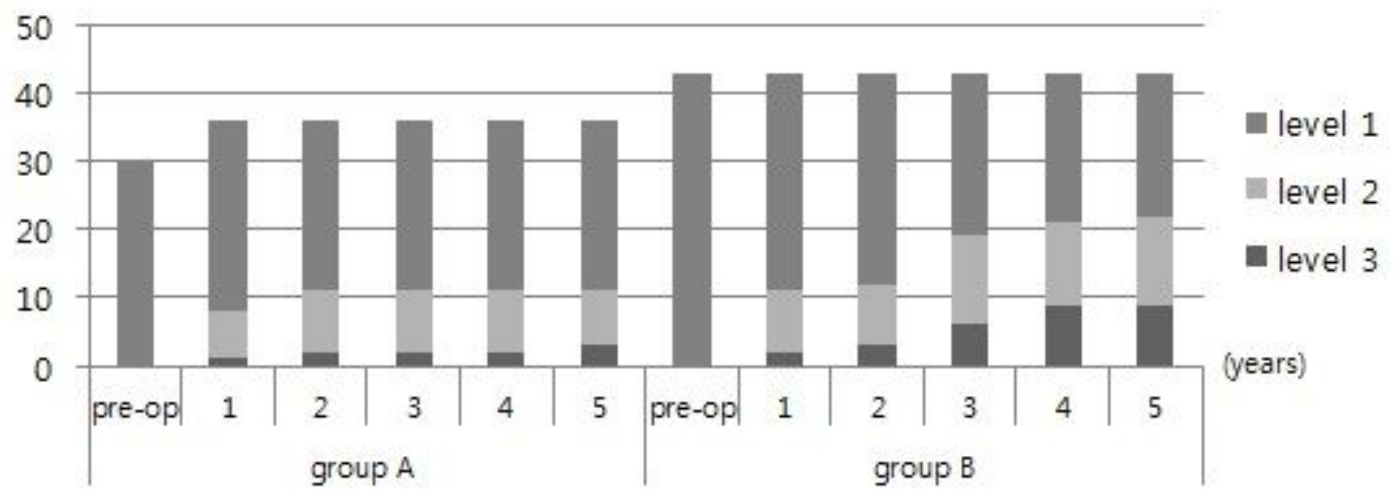

Figure 1 
Changes in hip function and walking grades. There is a significant decrease in hip function from 48 months postoperatively in Group B, and walking grades 2 and 3 in Group B increase from 48 months postoperatively.

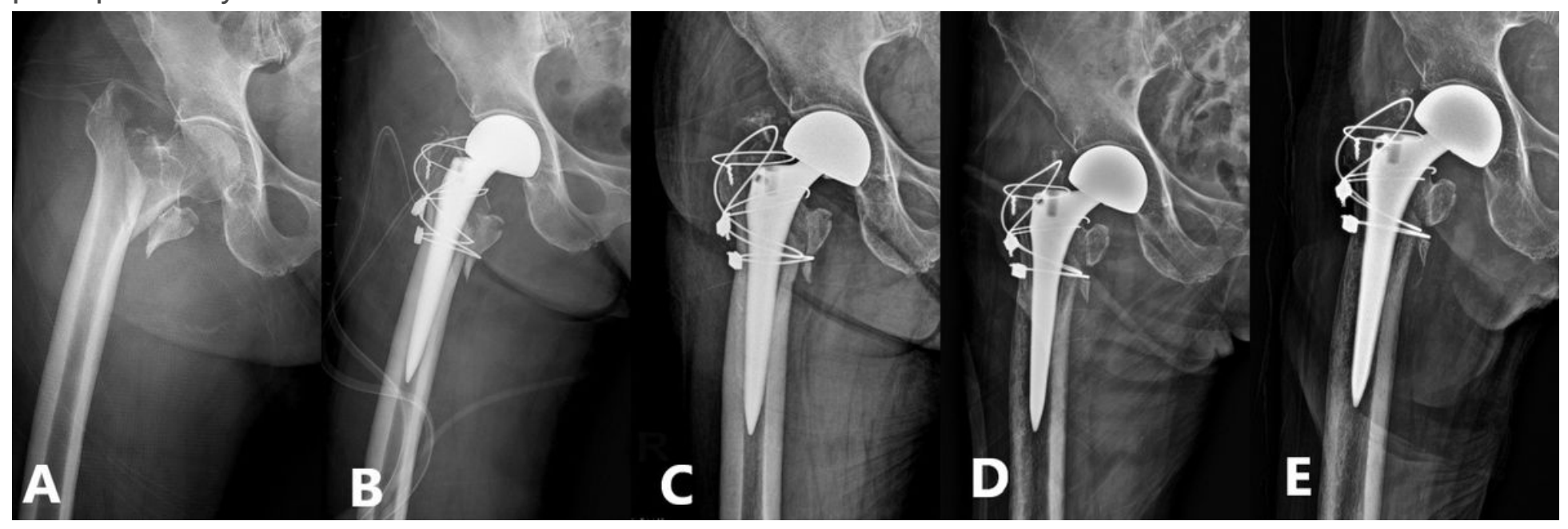

\section{Figure 2}

Representative case in Group A. A) A2-type intertrochanteric fracture in an 81-year-old female patient. B) Postoperative radiograph of a $3 \mathrm{C}$ stem. C) Follow-up at 12 months showing stable fixation of the femoral stem without any cortical porosis and radiolucent lines. D) Follow-up at 24 months showing cortical porosis around the femoral stem with stable fixation. E) Follow-up at 60 months showing stable fixation of the femoral stem and persistent cortical porosis without radiolucent lines.

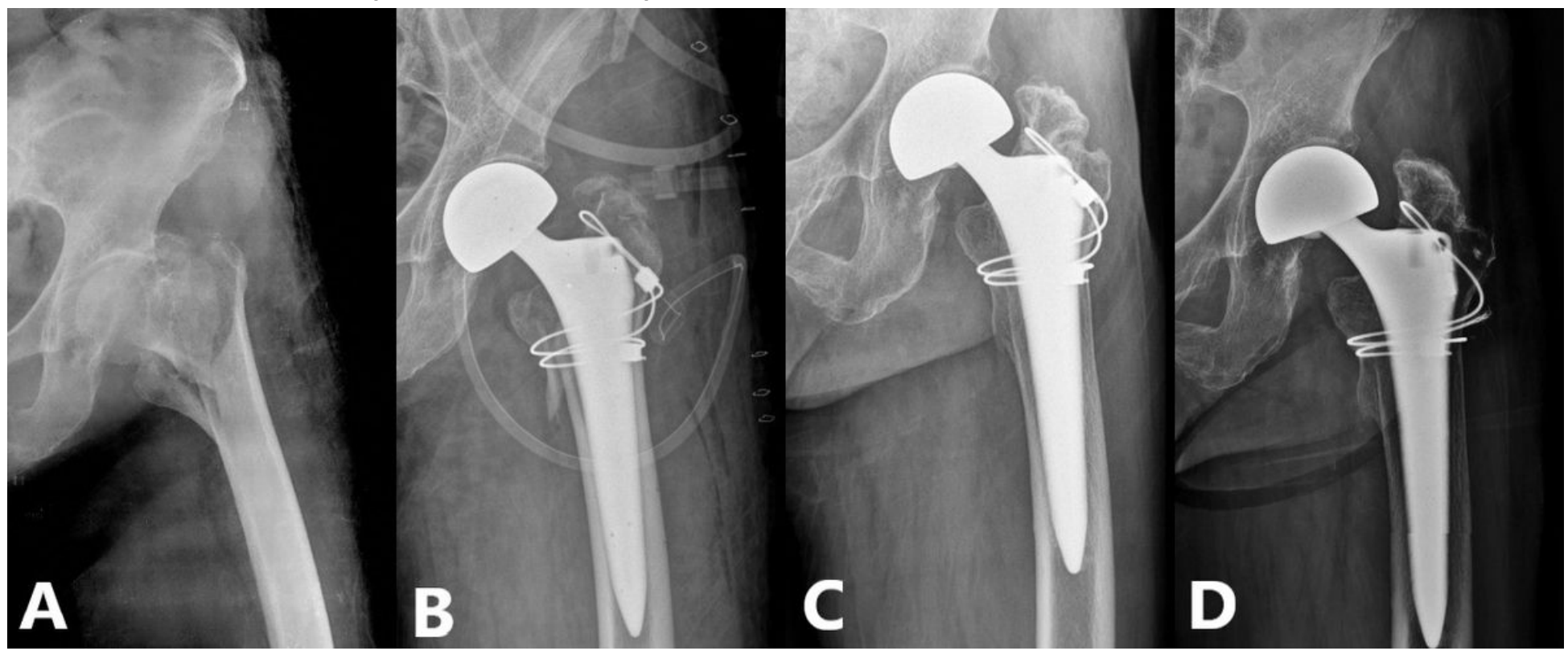

\section{Figure 3}

Representative case in Group B. A) A2-type intertrochanteric fracture in a 79-year-old female patient. B) Postoperative radiograph of a $3 \mathrm{C}$ stem. C) Follow-up at 12 months showing some cortical porosis around 
the femoral stem with stable fixation and a united greater trochanter. D) Follow-up at 60 months showing a radiolucent line at the bone-stem interface with a united greater trochanter.

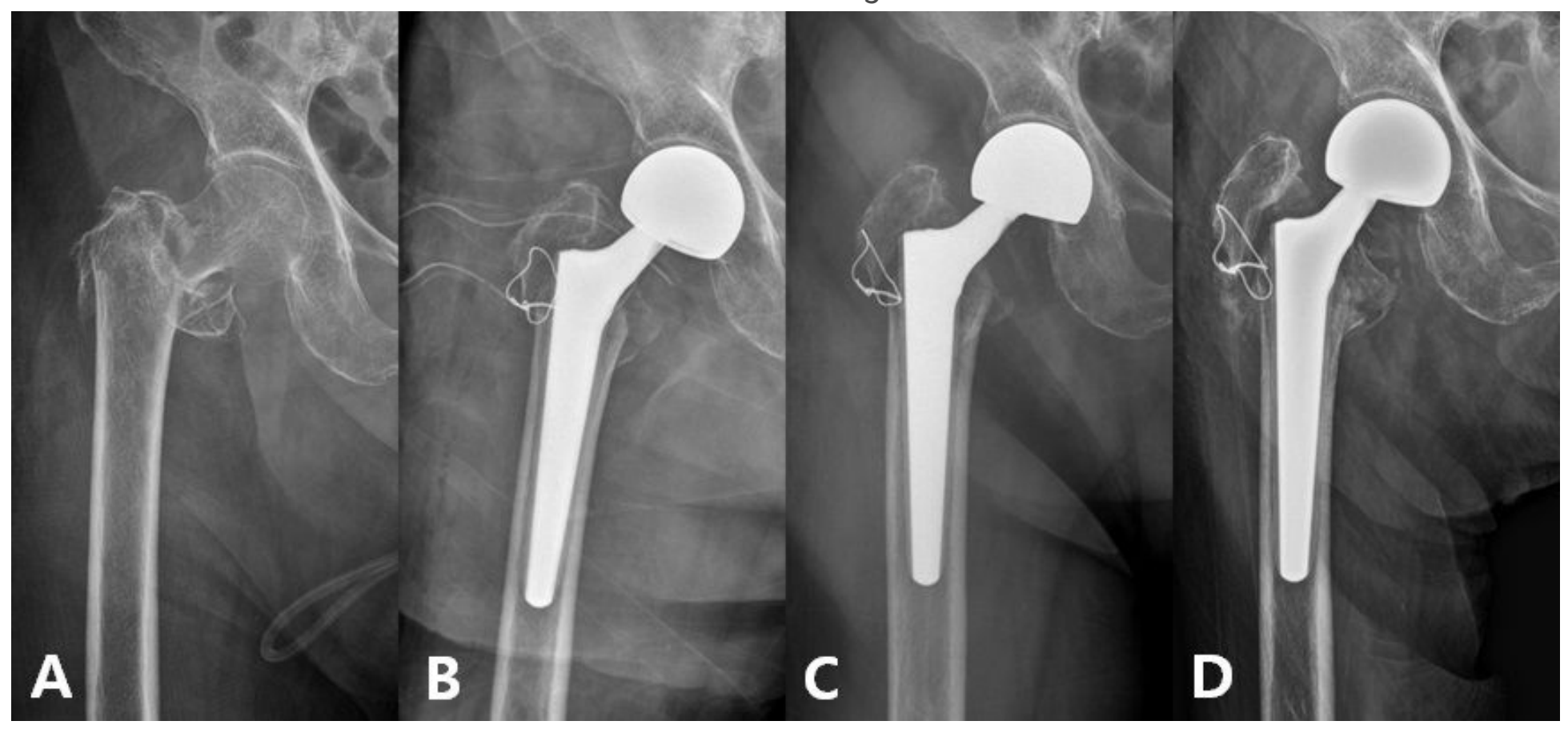

\section{Figure 4}

Representative patient with trochanteric nonunion. A) A3-type intertrochanteric fracture in an 82-year-old female patient. B) Postoperative radiograph of a 3B stem. C) Follow-up at 36 months showing stable fixation of the femoral stem. D) Follow-up at 60 months showing stable fixation of the femoral stem and a non-united greater trochanter without any cortical porosis and radiolucent lines. 